\title{
Physical Activity Levels and Screen Time among Youth with Overweight/Obesity Using Mental Health Services
}

\author{
Gerald J. Jerome ${ }^{1, *(D)}$, Tyler Fink ${ }^{2}$, Tammy Brady ${ }^{3}$, Deborah R. Young ${ }^{4}$, Faith B. Dickerson ${ }^{5}$, Stacy Goldsholl ${ }^{2}$, \\ Robert L. Findling ${ }^{6}{ }^{D}$, Ekaterina A. Stepanova ${ }^{6}$, Ann Scheimann ${ }^{3}$, Arlene T. Dalcin ${ }^{2}$, Alison Terry ${ }^{2}$, \\ Joseph Gennusa ${ }^{2}$, Courtney Cook ${ }^{2}$, Gail L. Daumit ${ }^{2,+}$ and Nae-Yuh Wang ${ }^{2,7,+}$
}

Citation: Jerome, G.J.; Fink, T.; Brady, T.; Young, D.R.; Dickerson, F.B.; Goldsholl, S.; Findling, R.L.;

Stepanova, E.A.; Scheimann, A.; Dalcin, A.T.; et al. Physical Activity Levels and Screen Time among Youth with Overweight/Obesity Using Mental Health Services. Int. J. Environ. Res. Public Health 2022, 19, 2261. https://doi.org/10.3390/ ijerph19042261

Academic Editor: Mário António Cardoso Marques

Received: 16 December 2021

Accepted: 8 February 2022

Published: 17 February 2022

Publisher's Note: MDPI stays neutral with regard to jurisdictional claims in published maps and institutional affiliations.

Copyright: (C) 2022 by the authors. Licensee MDPI, Basel, Switzerland. This article is an open access article distributed under the terms and conditions of the Creative Commons Attribution (CC BY) license (https:// creativecommons.org/licenses/by/ $4.0 /)$.
1 Department of Kinesiology, Towson University, Towson, MD 21252, USA

2 Division of General Internal Medicine, Johns Hopkins School of Medicine, Baltimore, MD 21205, USA; tfink1@jhmi.edu (T.F.); sgoldsh1@jhmi.edu (S.G.); adalcin1@jh.edu (A.T.D.); aterry11@jhmi.edu (A.T.); jgennus1@jhmi.edu (J.G.); ccook17@jhmi.edu (C.C.); gdaumit@jhmi.edu (G.L.D.); naeyuh@jhmi.edu (N.-Y.W.)

3 Department of Pediatrics, Johns Hopkins School of Medicine, Baltimore, MD 21287, USA; tbrady8@jhmi.edu (T.B.); ascheima@jhmi.edu (A.S.)

4 Kaiser Permanente Southern California, Pasadena, CA 91101, USA; deborah.r.young@kp.org

5 Sheppard Pratt, Baltimore, MD 21204, USA; faithbdickerson@gmail.com

6 Department of Psychiatry, Virginia Commonwealth University, Richmond, VA 23284, USA; robert.findling@vcuhealth.org (R.L.F.); ekaterina.stepanova@vcuhealth.org (E.A.S.)

7 Department of Biostatistics and Epidemiology, Johns Hopkins Bloomberg School of Public Health, Baltimore, MD 21205, USA

* Correspondence: gjerome@towson.edu

+ These authors contributed equally to this work.

Abstract: Youth with mental illness have higher levels of obesity than children in the general population. Both regular physical activity and limited screen time have been recommended to reduce and prevent childhood obesity. This study examines accelerometer-based moderate-vigorous physical activity (MVPA) and screen time among youth with overweight/obesity issues who are receiving mental health care. This study looked at a 12-month weight management randomized clinical trial for overweight/obese youth aged 8-18 years who are receiving mental health services. At baseline, MVPA was assessed using accelerometers, and screen time was self-reported. Among 100 youth, $43 \%$ were female, $44 \%$ were Black, and $48 \%$ were $<13$ years old. In an adjusted general linear model, higher levels of MVPA were associated with the younger age group $(p=0.012)$, male participants $(p=0.013)$, and lower BMI z-scores $(p=0.014)$. In a separate model, higher screen time was associated with participants who were Black $(p=0.007)$. Achieving optimal cardiovascular health at the population level requires an understanding of the groups that are most in need of additional assistance. These data reinforce that targeted lifestyle approaches to promote increased physical activity and decreased screen time among overweight/obese youth using mental health services may need additional tailoring for sex, age, and race subgroups.

Keywords: physical activity; children; adolescent; obesity; mental health

\section{Introduction}

Childhood obesity is a significant public health concern [1-3]. The prevalence of overweight and obesity among youth with mental illness is substantially greater than the overall pediatric prevalence [4-6]. The impact of childhood obesity on this group is particularly concerning for two reasons. First, there is an increased risk of adult obesity for youth with obesity [6,7]. Second, adults with serious mental illness (SMI) have high rates of obesity and related premature mortality due to cardiovascular disease (CVD), and youth with mental illness are more likely to have mental illness as an adult [8-10]. 
Physical activity has been identified as a key health behavior to address childhood obesity [11,12]. Limiting screen time has also been recommended to reduce and prevent childhood obesity [11,12]. Guidelines recommend youth accumulate $60 \mathrm{~min} /$ day of physical activity and limit screen time [11-13]. Despite the documented benefits and corresponding guidelines, the physical activity levels of youth in the United States remain low. One report estimated that only $26 \%$ of youth engage in $60 \mathrm{~min} /$ day of physical activity and there is evidence that physical activity levels vary by sex, race, and age subgroups [14,15]. Only $32 \%$ of youth in the United States report two or less hours of screen time per day [15]. Among adolescents, declines in physical activity have been associated with depressive symptoms [16]. A prospective cohort study indicated that sedentary behavior increases throughout adolescence and was associated with a greater risk of depressive symptoms [17]. Sedentary behavior has also been linked to anxiety symptoms among youth [18]. These studies and much of the research examining physical activity and mood in adolescents have been centered on the overall population $[19,20]$. Little is known about the physical activity levels and screen time of youth using specialty mental health services, including those with mood disorders, anxiety disorders, or attention-deficit/hyperactivity disorder. These youth receiving care in mental health clinics are likely to have more serious mental health concerns and belong to the group that has mental illness as adults [10]. Research indicates that adults with serious mental illness have lower levels of physical activity than the general population [21]. This study is an important step towards understanding physical activity levels in youth using specialty mental health services, which are an at-risk group for premature CVD risk. Achieving optimal cardiovascular health at the population level will require early intervention, especially among high-risk groups [4,22].

This study examines accelerometer-based physical activity levels and self-reported screen time among overweight/obese youth who were receiving specialty mental health care. The participants were enrolled in a randomized clinical trial testing a weight management program for overweight and obese youth with mental illness. The primary aim of these secondary analyses was to report baseline accelerometer-based physical activity levels and self-reported screen time among participants. A secondary aim was to examine physical activity levels and screen time among age, sex, race, and psychiatric diagnosis subgroups.

\section{Materials and Methods}

\subsection{Study Overview}

The baseline data used for these analyses were from a 12-month weight management trial for youth aged $8-18$ years who were receiving specialty mental health services. The core design was a two-arm clinical trial randomized by individual, with an intervention group and a usual care control group (NCT03075306). The intervention group received a weight management program that included sessions with coaches to encourage the adoption of dietary and physical activity changes to achieve a healthy weight. These sessions were either conducted in the participant's home or remotely using telephone and video conferencing. The primary outcome was change in BMI z-score at 12 months.

\subsection{Participants and Settings}

One hundred twelve youth aged 8-18 years with BMI z-score $\geq 85 \%$ for age and sex were recruited from participating outpatient mental health clinics. Participants had to be receiving specialty mental health care from a participating center for inclusion. Exclusion criteria included developmental delay precluding completion of study procedures, history of substance-related disorder or a genetic disorder of obesity, weight in excess of 400 pounds, chronic use of non-psychiatric medication associated with weight gain, $\geq 5 \%$ weight loss within the last 6 months, pregnancy or nursing, planning to end care at the clinic within 6 months, or plans to move from the geographic area within 12 months. These analyses included participants who met the minimum accelerometer wear time requirement as described below. 


\subsection{Measures}

Parents self-reported demographics and chart review provided the primary clinical mental health diagnoses. Race was reported using the following categories: Black; Hispanic/Latino, not Black; White/Caucasian, not Hispanic/Latino; and Other. Standardized procedures were used to assess participant height and weight. Overweight was defined as an age-sex specific BMI percentile between $85 \%$ and $94 \%$ and obesity was defined as $\geq 95$ th percentile [11].

We assessed self-reported screen time using a modified screen time questionnaire [23]. This version included the original three activities (watching TV/DVDs/videos, using a computer not for homework, and using Xbox/PlayStation or other electronic games when sitting) plus an item regarding the use of cellphones or tablets. Each questionnaire item assessed $\mathrm{h}$ /day $(0,0.5,1,2,3,4,5+)$ for an average weekday and weekend day. We calculated a weighted daily average $((5 \times$ weekday hours $+2 \times$ weekend hours $) / 7)$.

Physical activity was assessed using an accelerometer (Actigraph wGT3X-BT, Pensacola, FL, USA). Participants were asked to wear the accelerometer on the waist during waking hours across a seven-day period. Minimum wear time was $10 \mathrm{~h} /$ day for four days and we used the Evenson cut-points for physical activity intensity [24]. We reported average $\mathrm{min} /$ day of vigorous, moderate, and moderate-to-vigorous physical activity (MVPA).

\subsection{Statistical Analyses}

We compared between-group differences using Fisher's exact tests for categorical variables and Welch's $t$-test for continuous variables. We verified $t$-test results by performing sensitivity analyses for the $t$-tests, re-examining mean outcomes when extreme values (greater than 1.5 IQR) were excluded. Using separate general linear models (GLMs), an approach that allows for both categorical and continuous predictors and relaxes the normal distribution assumption, we examined the relationship between participants' characteristics and the outcomes of MVPA and screen time while adjusting for other characteristics in the model. Due to small sample sizes in the race/ethnicity subgroups we examined the multivariable modeling focused on race. Similarly, due to sample size, the other diagnosis category was combined with the anxiety category in the multivariable modeling. The model was coded as $(0,1)$ for age (younger and older age groups), sex (females and males), and race (non-Black and Black), respectively. We reported results for the adjusted model. For categorical variables that had more than two categories (e.g., diagnosis), we reported a chi-square $p$-value for the overall test of association. We examined age by diagnosis interactions and only included statistically significant interaction terms in the final model. The GLM model assumptions were verified by examining the residuals of the models, and sensitivity analyses were conducted excluding extreme values. Analyses were conducted using R (R Foundation for Statistical Computing, Vienna, Austria).

\subsection{Ethics Statement}

This study was carried out in accordance with the Declaration of Helsinki and the protocol was approved by the Johns Hopkins Medicine Institutional Review Board (130511, 12/2017). Written informed consent was obtained from the parents/guardians of all participants, and additional assent was obtained from all participants.

\section{Results}

Among the 112 participants enrolled in the trial, there were 100 participants at baseline who met minimal wear-time criteria of 4 days with at least $10 \mathrm{~h}$ of wear time per day, forming the analysis sample of this report. Among the 100 participants in these analyses, there was an average of 5.3 days $(S D=1.1)$ and $13.7 \mathrm{~h}$ /day of wear time $(\mathrm{SD}=1.7)$. All days with valid wear time were used in analyses. There were no differences in demographic characteristics between those included and those excluded from the analysis sample. The sample was $43 \%$ female, $44 \%$ Black, and $48 \%$ were aged 8-12 years (Table 1 ). The most prevalent primary diagnoses were attention-deficit/hyperactivity disorder (ADHD, 43\%), 
anxiety-related disorders (28\%), and depressive disorders (21\%). The distributions of diagnoses were different between the age groups $(p=0.048)$, such as a higher percentage of ADHD diagnosis in the younger age group compared to the older age group. The average BMI percentile was 96.4 , with $75 \%$ having a BMI percentile $\geq 95$ th percentile.

Table 1. Participant characteristics by age group.

\begin{tabular}{|c|c|c|c|c|}
\hline & \multirow[t]{2}{*}{ Total } & \multicolumn{2}{|c|}{ Age in Years } & \\
\hline & & $8-12$ & \multicolumn{2}{|l|}{$13-18$} \\
\hline & $N=100$ & $n=48$ & $\mathrm{n}=52$ & \\
\hline & n (\%) & n (\%) & n (\%) & $p^{1}$ \\
\hline Sex & & & & 0.317 \\
\hline Female & $43(43.0)$ & $18(37.5)$ & $25(48.1)$ & \\
\hline Income & & & & 0.558 \\
\hline$<\$ 25,000$ & $21(21.0)$ & $11(22.9)$ & $10(19.2)$ & \\
\hline$\$ 25,000-\$ 49,999$ & $18(18.0)$ & $10(20.8)$ & $8(15.4)$ & \\
\hline$\$ 50,000-\$ 74,999$ & $13(13.0)$ & $4(8.3)$ & $9(17.3)$ & \\
\hline$\geq \$ 75,000$ & $47(47.0)$ & $23(47.9)$ & $24(46.2)$ & \\
\hline Race & & & & 0.282 \\
\hline Black & $44(44.0)$ & $21(43.8)$ & $23(44.2)$ & \\
\hline White/Caucasian & $46(46.0)$ & $25(52.1)$ & $21(40.4)$ & \\
\hline Hispanic/Latino & $5(5.0)$ & $1(2.1)$ & $4(7.7)$ & \\
\hline Other & $5(5.0)$ & $1(2.1)$ & $4(7.7)$ & \\
\hline Psychiatric Diagnosis & & & & 0.048 \\
\hline ADHD & $43(43.0)$ & $27(56.2)$ & $16(30.8)$ & \\
\hline Anxiety & $28(28.0)$ & $11(22.9)$ & $17(32.7)$ & \\
\hline Depression & $21(21.0)$ & $6(12.5)$ & $15(28.8)$ & \\
\hline Other & $8(8.0)$ & $4(8.3)$ & $4(7.7)$ & \\
\hline & $\mathrm{M}(\mathrm{SD})$ & $\mathrm{M}(\mathrm{SD})$ & $\mathrm{M}(\mathrm{SD})$ & \\
\hline Body Mass Index & & & & \\
\hline BMI z-score & $2.0(0.5)$ & $2.0(0.4)$ & $2.0(0.5)$ & 0.600 \\
\hline BMI percentile & $96.4(3.6)$ & $96.7(3.1)$ & $96.1(3.9)$ & 0.418 \\
\hline
\end{tabular}

${ }_{1}^{1} p$ indicates between-group differences. Fisher's exact tests were used for categorical variables and $t$-tests were used for continuous variables.

Figure 1 displays physical activity and screen time by age group. Overall, participants averaged $34.6(\mathrm{SD}=18.1) \mathrm{min} /$ day of MVPA and $8.58(\mathrm{SD}=5.2) \mathrm{h} /$ day of screen time. Compared to youth aged 13-18 years, the youth aged 8-12 years had higher MVPA $(\mathrm{M}=39.9, \mathrm{SD}=19.2$ versus $\mathrm{M}=29.7, \mathrm{SD}=15.6, p=0.005)$ and higher moderate-intensity physical activity $(\mathrm{M}=31.2, \mathrm{SD}=13.9$ versus $\mathrm{M}=23.1, \mathrm{SD}=11.6, p=0.002)$. The $t$-tests indicated no differences in screen time $(\mathrm{M}=7.6, \mathrm{SD}=5.2$ versus $\mathrm{M}=9.5, \mathrm{SD}=5.1, p=0.060)$ or vigorous physical activity $(\mathrm{M}=8.8, \mathrm{SD}=6.1$ versus $\mathrm{M}=6.6, \mathrm{SD}=6.2, p=0.080)$ for the younger and older age groups, respectively. Sensitivity analyses that excluded participants with extreme scores indicated no change in the $t$-test results for the physical activity but resulted in a significant difference in screen time by age group.

Table 2 shows the adjusted GLM models for the association between participant characteristics and both physical activity and screen time. Neither model had a significant diagnosis by age group interaction. Consequently, the interaction was not included in the final model. Higher levels of MVPA were associated with the younger age group $(p=0.012)$, male participants $(p=0.013)$, and having a lower BMI z-score $(p=0.014)$. Diagnosis was associated with MVPA $(p=0.034)$, and the model indicated that those with anxiety or other diagnoses had lower activity levels than those with an ADHD diagnosis. No other differences between diagnoses were identified. Higher screen time was associated with participants who were Black $(p=0.007)$. Sensitivity analyses that excluded individuals with extreme residual scores indicated no difference in the reported GLM results. Additional sensitivity analyses that included 10 participants with 3 days of $\geq 10 \mathrm{~h}$ of accelerometer wear time were also aligned with the physical activity GLM results. This sensitivity 
analysis resulted in higher screen time being associated with both the older age group and participants who were Black.

A. Moderate-Vigorous PA by Age

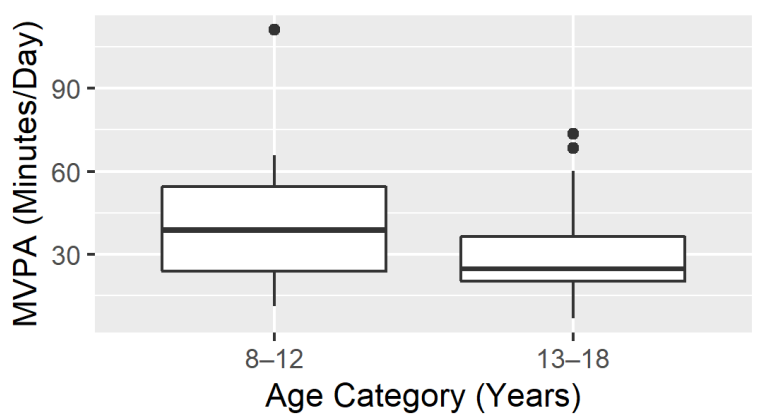

C. Moderate PA by Age

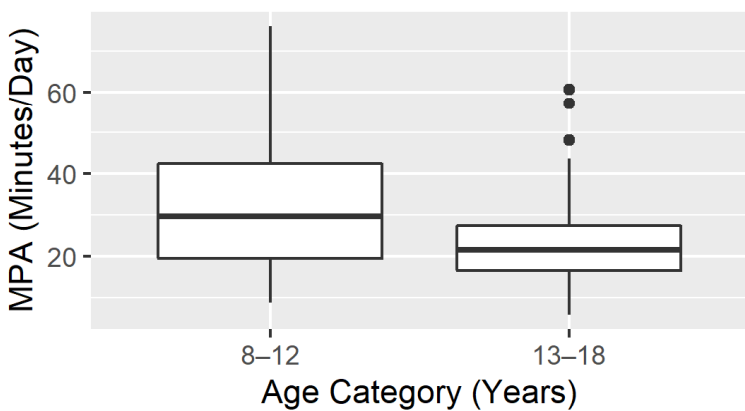

B. Vigorous PA by Age
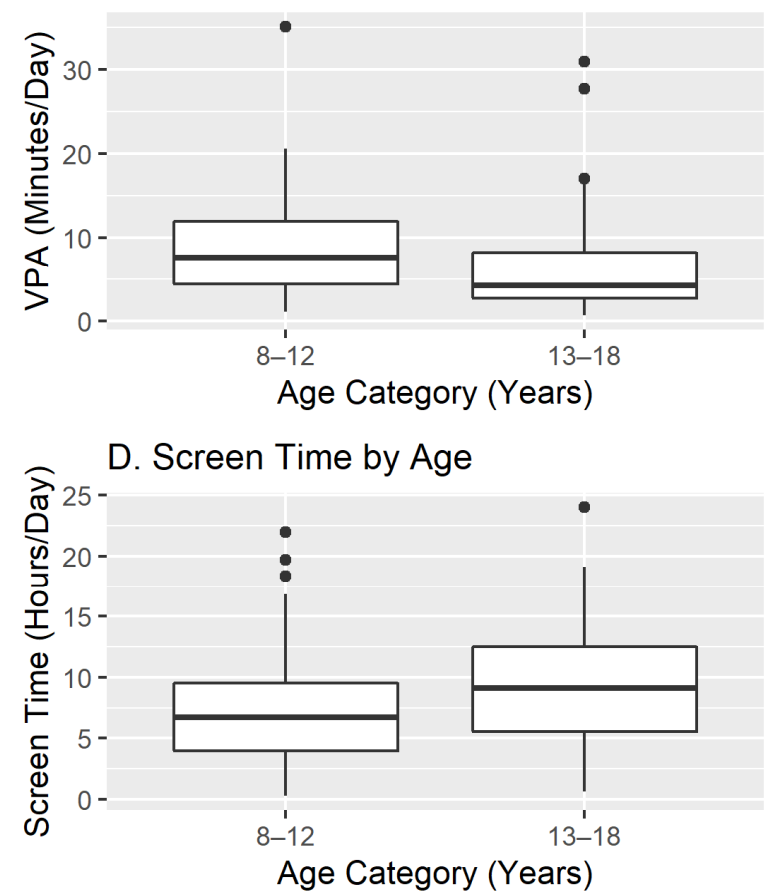

Figure 1. Physical activity and screen time by age group.

Table 2. Association of physical activity and screen time with participant characteristics.

\begin{tabular}{|c|c|c|c|c|c|c|}
\hline \multirow[t]{2}{*}{$\begin{array}{c}\text { Participant } \\
\text { Characteristic }\end{array}$} & \multicolumn{3}{|c|}{$\begin{array}{l}\text { Moderate-to-Vigorous } \\
\text { Physical Activity }\end{array}$} & \multicolumn{3}{|c|}{ Screen Time } \\
\hline & $\beta$ & $95 \%$ CI & $p^{1}$ & $\beta$ & $95 \%$ CI & $p^{1}$ \\
\hline Intercept & 54.2 & $(37.8,70.6)$ & $<0.001$ & 0.6 & $(-4.5,5.6)$ & 0.829 \\
\hline \multicolumn{7}{|l|}{ Age Group } \\
\hline $8-12$ years & ref & & & ref & & \\
\hline 13-18 years & -8.5 & $(-15.1,-2.0)$ & 0.012 & 1.9 & $(-0.1,3.9)$ & 0.063 \\
\hline \multicolumn{7}{|l|}{ Sex } \\
\hline Female & ref & & & ref & & \\
\hline Male & 9.4 & $(2.1,16.6)$ & 0.013 & 1.9 & $(-0.3,4.1)$ & 0.101 \\
\hline \multicolumn{7}{|l|}{ Race } \\
\hline Non-Black & ref & & & ref & & \\
\hline Black & 4.4 & $(-2.0,10.9)$ & 0.179 & 2.8 & $(0.8,4.7)$ & 0.007 \\
\hline Diagnosis & & & $0.034^{2}$ & & & $0.345^{2}$ \\
\hline ADHD & ref & & & ref & & \\
\hline Anxiety & -9.8 & $(-17.7,-1.9)$ & & 1.8 & $(-0.6,4.2)$ & \\
\hline Depression & -1.6 & $(-11.0,7.8)$ & & 1.0 & $(-1.9,3.8)$ & \\
\hline BMI z-score & -9.5 & $(-16.9,-2.1)$ & 0.014 & 1.9 & $(-0.04,4.2)$ & 0.102 \\
\hline
\end{tabular}

${ }^{1} p$-Values represent pairwise comparison with the reference category. ${ }^{2}$ Overall test examining chi-square $p$-value with d.f. $=2$.

There were 11 participants who met the physical activity guidelines of at least $60 \mathrm{~min} /$ day of MVPA. Seven were in the younger age group. Eight participants met the guidelines of less than $2 \mathrm{~h}$ /day of screen time, six of whom were in the younger age group. The only participant who met both guidelines was in the younger age group. 


\section{Discussion}

We examined physical activity and screen time at baseline in a weight management trial for overweight/obese youth aged 8-18 years with mental illness receiving specialty mental health services. Only approximately one-tenth of the study sample met physical activity guidelines of at least $60 \mathrm{~min} /$ day of physical activity and eight percent met the screen time recommendation of less than $2 \mathrm{~h} /$ day. Overall, only one percent of participants met both daily physical activity and screen time recommendations. These are lower than rates reported in the International Study of Childhood Obesity, Lifestyle, and the Environment where $7.2 \%$ of U.S. children and $14.5-20.8 \%$ of children in industrialized countries aged 9-11 years met both physical activity and screen time recommendations [15]. In the current study only $15 \%$ of 8-12-year-olds met physical activity guidelines, which is substantially lower than national estimates of between $26.5 \%$ and $42 \%$ of pre-teen youth reporting meeting physical activity guidelines $[15,25]$. Interestingly, only $8 \%$ of youth above the age of 12 in the general population met the guidelines, which aligned with the findings in our study [25]. This is one of the first reports of objectively measured physical activity levels among children with mental illness using specialty mental health services. These results substantiate that national concerns regarding low levels of physical activity among youth should be heightened in this group with mental illness.

Overall, $8 \%$ of participants met the recommendation of less than $2 \mathrm{~h} /$ day of screen time, with a higher rate reported among the younger age group (12.5\%). As with physical activity, this is substantially lower than national estimates, which indicate $26.5-76.4 \%$ of children met this screen time recommendation $[15,26]$. Participants who were Black reported more screen time than other participants, identifying the need for tailored interventions and support. Limiting screen time is a recommended strategy for addressing obesity among youth, and evidence suggests it may also have mental health benefits [11-13,26,27]. As both physical activity and screen time are modifiable factors associated with obesity, they appear to be highly relevant targets for lifestyle interventions in this group.

Reports have associated depressive and anxiety-related symptoms with lower physical activity in youth, but the underlying mechanisms are not clear [17,18]. One study indicated youth with ADHD were less likely to play sports, which may contribute to lower physical activity levels [28]. A survey of teens and young adults receiving mental health services indicated interest in physical activity promotion being offered in conjunction with mental health services [29]. However, interest in physical activity was inversely related to the participant's perception of exercise benefits and self-rated autonomy toward exercising. Parker et al. suggested the use of a collaborative problem-solving process to promote physical activity among young people using mental health services [29].

The current analyses were conducted among overweight/obese youth engaged in mental health clinics who enrolled in a weight management study. Although being in a study testing an intervention may limit the generalizability of the findings, these baseline analyses focused on youth who, because of their overweight/obesity, are likely to have a significant benefit from increased physical activity and decreased screen time. The trial was not powered for these secondary analyses, and multiple-comparison adjustments were not performed. Further research should confirm these findings with a sufficient sample size for subgroup comparisons. Longitudinal investigation may provide greater insight into the unique challenges this group faces as well as modifiable factors associated with higher physical activity and lower screen time. The authors are not aware of other reports of screen time and objectively measured physical activity among youth with mental illness in specialty mental health care. Strengths of this study included the objective assessment of physical activity and the diversity of the study population in terms of age, race, and primary diagnosis.

Based on self-report from parents, one in twenty children in the United States have problems with anxiety or depression, which has also been associated with a greater need for medical care or care coordination compared to children without anxiety- or depressionrelated problems [30]. Moreover, there are concerns about the long-term effect of COVID-19 
on the mental health of youth [31]. Reviews consistently note that higher levels of physical activity are associated with better mental health among youth (e.g., lower anxiety symptoms, lower depressive symptoms) [32,33]. For example, youth aged 7 and 14 years who met the $60 \mathrm{~min} /$ day of MVPA guideline had lower risk of depression [34]. There is evidence that both regular physical activity and limited screen time have mental health benefits among youth [32,33]. Additionally, there is evidence that aerobic exercise can help reduce the symptoms of ADHD [35]. With only $11 \%$ of the participants in the current study meeting physical activity recommendations, interventions increasing daily physical activity and decreasing screen time may confer substantial mental and physical health benefits among youth using mental health services. Unfortunately, research examining the mental health benefits of physical activity for children and adolescents lags behind research among adults in this area $[13,32,33]$. Determining the most effective mode and dose of physical activity in order to improve the mental health and physical health of youth, particularly among those with diagnosed mental illness, deserves further investigation $[13,32,33]$.

\section{Conclusions}

In 2015, the American Heart Association (AHA) called attention to mental illnesses in youth as important risk conditions for early CVD, and declared the need for transformational change in the screening and management of overweight and obesity in this population [4]. In addition, we need to provide early treatment of CVD risk factors in order to achieve public health objectives related to improving cardiovascular health [22]. Achieving optimal cardiovascular health at the population level not only requires early intervention, but also an understanding of high-risk groups that may need additional assistance in achieving this goal. In order to achieve equity in mental and physical health, additional efforts are needed to identify and assist youth demonstrating the greatest need. Baseline data from this study indicate that youth with overweight/obesity and mental illness who are using specialty mental health services have lower levels of physical activity and higher levels of screen time compared to published age-related estimates in the general population. These results reinforce the need for targeted lifestyle approaches for this at-risk group. Among this at-risk group, additional support may be needed for sex, age, and race subgroups.

Author Contributions: Conceptualization, G.J.J., T.B., D.R.Y., F.B.D., R.L.F., A.S., A.T.D., E.A.S., G.L.D. and N.-Y.W.; methodology, G.J.J.; formal analysis, G.J.J., T.F., G.L.D. and N.-Y.W.; data curation, G.J.J., T.F., S.G., A.T., J.G. and C.C.; writing—original draft preparation, G.J.J., T.F. and G.L.D.; writing—review and editing, G.J.J., T.F., T.B., D.R.Y., S.G., F.B.D., R.L.F., A.S., A.T.D., C.C., E.A.S., G.L.D. and N.-Y.W.; project administration, S.G., J.G. and C.C.; funding acquisition, G.L.D. All authors have read and agreed to the published version of the manuscript.

Funding: This research was funded by the National Institutes of Health, National Institute of Mental Health, grant numbers 5P50MH115842 and 5R01MH110968.

Institutional Review Board Statement: The study was conducted according to the guidelines of the Declaration of Helsinki, and approved by the Institutional Review Board of Johns Hopkins Medicine (130511, 12/2017).

Informed Consent Statement: Written informed consent was obtained from the parents/guardians of all participants, and additional assent was obtained from all participants.

Data Availability Statement: Deidentified data may be available to researchers whose proposed use of the data has been approved and have an appropriate data access agreement along with an IRB approval.

Conflicts of Interest: All authors report additional NIH funding and/or grants pending. RLF reports a relationship with Acadia, Adamas, Aevi, Afecta, Akili, Alkermes, Allergan, American Academy of Child \& Adolescent Psychiatry, American Psychiatric Press, Arbor, Axsome, Daiichi-Sankyo, Emelex, Gedeon Richter, and Genentech that includes consulting or advisory, funding grants, and speaking and lecture fees. Robert L. Findling reports a relationship with Idorsia, Intra-Cellular 


\begin{abstract}
Therapies, Kempharm, Luminopia, Lundbeck, MedAvante-ProPhase, Merck, MJH Life Sciences, Neurim, Otsuka, PaxMedica, Pfizer, Physicians Postgraduate Press, Q BioMed, Receptor Life Sciences, Roche, and Sage that includes consulting or advisory, funding grants, and speaking and lecture fees. RLF reports a relationship with Signant Health, Sunovion, Supernus Pharmaceuticals, Syneos, Syneurx, Takeda, Teva, Tris, and Validus that includes funding grants and speaking and lecture fees. AS receives or has received research support received honoraria or acted as a consultant for Harmony Biosciences, Saniona Pharmaceuticals, Radius Pharmaceuticals, Millendo Pharmaceuticals, and the American board of pediatrics. TB is supported by Resolve to Save Lives, an initiative of Vital Strategies. Resolve to Save Lives is funded by grants from Bloomberg Philanthropies; the Bill and Melinda Gates Foundation; and Gates Philanthropy Partners, which is funded with support from the Chan Zuckerberg Foundation. TB has received honoraria from Springer Nature to co-edit a textbook, Pediatric Hypertension, and is a Medical Advisory Board member for the National Kidney Foundation of Maryland and Delaware. The authors declare no additional conflict of interest. The funders had no role in the design of the study; in the collection, analysis, or interpretation of data; in the writing of the manuscript; or in the decision to publish the results.
\end{abstract}

\title{
References
}

1. Hales, C.M.; Carroll, M.D.; Fryar, C.D.; Ogden, C.L. Prevalence of Obesity Among Adults and Youth: United States, 2015-2016; National Center for Health Statistics: Hyattsville, MD, USA, 2017; pp. 1-8.

2. Ogden, C.L.; Carroll, M.D.; Kit, B.K.; Flegal, K.M. Prevalence of childhood and adult obesity in the United States, $2011-2012$. JAMA 2014, 311, 806-814. [CrossRef] [PubMed]

3. Skinner, A.C.; Ravanbakht, S.N.; Skelton, J.A.; Perrin, E.M.; Armstrong, S.C. Prevalence of Obesity and Severe Obesity in US Children, 1999-2016. Pediatrics 2018, 141, e20173459. [CrossRef] [PubMed]

4. Goldstein, B.I.; Carnethon, M.R.; Matthews, K.A.; McIntyre, R.S.; Miller, G.E.; Raghuveer, G.; Stoney, C.M.; Wasiak, H.; McCrindle, B.W. Major Depressive Disorder and Bipolar Disorder Predispose Youth to Accelerated Atherosclerosis and Early Cardiovascular Disease: A Scientific Statement From the American Heart Association. Circulation 2015, 132, 965-986. [CrossRef] [PubMed]

5. Merikangas, A.K.; Mendola, P.; Pastor, P.N.; Reuben, C.A.; Cleary, S.D. The association between major depressive disorder and obesity in US adolescents: Results from the 2001-2004 National Health and Nutrition Examination Survey. J. Behav. Med. 2012, 35, 149-154. [CrossRef] [PubMed]

6. Natalie, T.S.; Suchindran, C.; North, K.E.; Popkin, B.M.; Gordon-Larsen, P. Association of adolescent obesity with risk of severe obesity in adulthood. JAMA 2010, 304, 2042-2047. [CrossRef]

7. Field, A.; Cook, N.; Gillman, M. Weight status in childhood as a predictor of becoming overweight or hypertensive in early adulthood. Obes. Res. 2005, 13, 163-169. [CrossRef]

8. Allison, D.B.; Newcomer, J.W.; Dunn, A.L.; Blumenthal, J.A.; Fabricatore, A.N.; Daumit, G.L.; Cope, M.B.; Riley, W.T.; Vreeland, B.; Hibbeln, J.R.; et al. Obesity Among Those with Mental Disorders A National Institute of Mental Health Meeting Report. Am. J. Prev. Med. 2009, 36, 341-350. [CrossRef]

9. Daumit, G.L.; Anthony, C.B.; Ford, D.E.; Fahey, M.; Skinner, E.A.; Lehman, A.F.; Hwang, W.; Steinwachs, D.M. Pattern of mortality in a sample of Maryland residents with severe mental illness. Psychiatry Res. 2010, 176, 242-245. [CrossRef]

10. Kessler, R.; Berglund, P.; Demler, O. Lifetime prevalence and age-of-onset distributions of DSM-IV disorders in the National Comorbidity Survey replication. Arch. Gen. Psychiatry 2005, 62, 593-602. [CrossRef]

11. Barlow, S.E. Expert committee recommendations regarding the prevention, assessment, and treatment of child and adolescent overweight and obesity: Summary report. Pediatrics 2007, 120 (Suppl. 4), S164-S192. [CrossRef]

12. Kavey, R.E.; Allada, V.; Daniels, S.R.; Hayman, L.L.; McCrindle, B.W.; Newburger, J.W.; Parekh, R.S.; Steinberger, J. Cardiovascular risk reduction in high-risk pediatric patients: A scientific statement from the American Heart Association Expert Panel on Population and Prevention Science; the Councils on Cardiovascular Disease in the Young, Epidemiology and Prevention, Nutrition, Physical Activity and Metabolism, High Blood Pressure Research, Cardiovascular Nursing, and the Kidney in Heart Disease; and the Interdisciplinary Working Group on Quality of Care and Outcomes Research: Endorsed by the American Academy of Pediatrics. Circulation 2006, 114, 2710-2738. [CrossRef] [PubMed]

13. Physical Activity Guidelines Advisory Committee. 2018 Physical Activity Guidelines Advisory Committee Scientific Report; Physical Activity Guidelines Advisory Committee: Washington, DC, USA, 2018.

14. Kann, L.; McManus, T.; Harris, W.A.; Shanklin, S.L.; Flint, K.H.; Queen, B.; Lowry, R.; Chyen, D.; Whittle, L.; Thornton, J.; et al. Youth Risk Behavior Surveillance-United States, 2017. MMWR Surveill. Summ. 2018, 67, 1-114. [CrossRef] [PubMed]

15. Roman-Vinas, B.; Chaput, J.P.; Katzmarzyk, P.T.; Fogelholm, M.; Lambert, E.V.; Maher, C.; Maia, J.; Olds, T.; Onywera, V.; Sarmiento, O.L.; et al. Proportion of children meeting recommendations for 24-hour movement guidelines and associations with adiposity in a 12-country study. Int. J. Behav. Nutr. Phys. Act. 2016, 13, 123. [CrossRef] [PubMed]

16. Motl, R.W.; Birnbaum, A.S.; Kubik, M.Y.; Dishman, R.K. Naturally occurring changes in physical activity are inversely related to depressive symptoms during early adolescence. Psychosom. Med. 2004, 66, 336-342. [CrossRef]

17. Kandola, A.; Lewis, G.; Osborn, D.P.J.; Stubbs, B.; Hayes, J.F. Depressive symptoms and objectively measured physical activity and sedentary behaviour throughout adolescence: A prospective cohort study. Lancet Psychiatry 2020, 7, 262-271. [CrossRef] 
18. Kandola, A.; Lewis, G.; Osborn, D.P.J.; Stubbs, B.; Hayes, J.F. Device-measured sedentary behaviour and anxiety symptoms during adolescence: A 6-year prospective cohort study. Psychol. Med. 2020, 18, 1-10. [CrossRef]

19. Brown, H.E.; Pearson, N.; Braithwaite, R.E.; Brown, W.J.; Biddle, S.J. Physical activity interventions and depression in children and adolescents : A systematic review and meta-analysis. Sports Med. 2013, 43, 195-206. [CrossRef]

20. Dale, L.P.; Vanderloo, L.; Moore, S.; Faulkner, G. Physical activity and depression, anxiety, and self-esteem in children and youth: An umbrella systematic review. Ment. Health Phys. Act. 2019, 16, 66-79. [CrossRef]

21. Daumit, G.L.; Goldberg, R.W.; Anthony, C.; Dickerson, F.; Brown, C.H.; Kreyenbuhl, J.; Wohlheiter, K.; Dixon, L.B. Physical activity patterns in adults with severe mental illness. J. Nerv. Ment. Dis. 2005, 193, 641-646. [CrossRef]

22. Goff, D.C., Jr.; Khan, S.S.; Lloyd-Jones, D.; Arnett, D.K.; Carnethon, M.R.; Labarthe, D.R.; Loop, M.S.; Luepker, R.V.; McConnell, M.V.; Mensah, G.A.; et al. Bending the Curve in Cardiovascular Disease Mortality: Bethesda +40 and Beyond. Circulation 2021, 143, 837-851. [CrossRef]

23. Berge, J.M.; Wall, M.; Larson, N.; Loth, K.A.; Neumark-Sztainer, D. Family functioning: Associations with weight status, eating behaviors, and physical activity in adolescents. J. Adolesc. Health 2013, 52, 351-357. [CrossRef] [PubMed]

24. Evenson, K.R.; Catellier, D.J.; Gill, K.; Ondrak, K.S.; McMurray, R.G. Calibration of two objective measures of physical activity for children. J. Sports Sci. 2008, 26, 1557-1565. [CrossRef] [PubMed]

25. Troiano, R.P.; Berrigan, D.; Dodd, K.W.; Masse, L.C.; Tilert, T.; McDowell, M. Physical activity in the United States measured by accelerometer. Med. Sci. Sports Exerc. 2008, 40, 181-188. [CrossRef] [PubMed]

26. Huhman, M.; Lowry, R.; Lee, S.M.; Fulton, J.E.; Carlson, S.A.; Patnode, C.D. Physical activity and screen time: Trends in U.S. children aged 9-13 years, 2002-2006. J. Phys. Act. Health 2012, 9, 508-515. [CrossRef]

27. Hrafnkelsdottir, S.M.; Brychta, R.J.; Rognvaldsdottir, V.; Gestsdottir, S.; Chen, K.Y.; Johannsson, E.; Guethmundsdottir, S.L.; Arngrimsson, S.A. Less screen time and more frequent vigorous physical activity is associated with lower risk of reporting negative mental health symptoms among Icelandic adolescents. PLoS ONE 2018, 13, e0196286. [CrossRef]

28. Tandon, P.S.; Sasser, T.; Gonzalez, E.S.; Whitlock, K.B.; Christakis, D.A.; Stein, M.A. Physical Activity, Screen Time, and Sleep in Children With ADHD. J. Phys. Act. Health 2019, 16, 416-422. [CrossRef]

29. Parker, A.G.; Trott, E.; Bourke, M.; Klepac Pogrmilovic, B.; Dadswell, K.; Craike, M.; McLean, S.A.; Dash, S.; Pascoe, M. Young people's attitudes towards integrating physical activity as part of mental health treatment: A cross-sectional study in youth mental health services. Early Interv. Psychiatry 2021, 19, 1-9. [CrossRef]

30. Bitsko, R.H.; Holbrook, J.R.; Ghandour, R.M.; Blumberg, S.J.; Visser, S.N.; Perou, R.; Walkup, J.T. Epidemiology and Impact of Health Care Provider-Diagnosed Anxiety and Depression Among US Children. J. Dev. Behav. Pediatrics JDBP 2018, 39, $395-403$. [CrossRef]

31. Meherali, S.; Punjani, N.; Louie-Poon, S.; Abdul Rahim, K.; Das, J.K.; Salam, R.A.; Lassi, Z.S. Mental Health of Children and Adolescents Amidst COVID-19 and Past Pandemics: A Rapid Systematic Review. Int. J. Environ. Res. Public Health 2021, $18,3432$. [CrossRef]

32. Biddle, S.J.; Asare, M. Physical activity and mental health in children and adolescents: A review of reviews. Br. J. Sports Med. 2011, 45, 886-895. [CrossRef]

33. Pascoe, M.; Bailey, A.P.; Craike, M.; Carter, T.; Patten, R.; Stepto, N.; Parker, A. Physical activity and exercise in youth mental health promotion: A scoping review. BMJ Open Sport Exerc. Med. 2020, 6, e000677. [CrossRef] [PubMed]

34. Hamer, M.; Patalay, P.; Bell, S.; Batty, G.D. Change in device-measured physical activity assessed in childhood and adolescence in relation to depressive symptoms: A general population-based cohort study. J. Epidemiol. Community Health 2020, 74, 330-335. [CrossRef] [PubMed]

35. Ng, Q.X.; Ho, C.Y.X.; Chan, H.W.; Yong, B.Z.J.; Yeo, W.S. Managing childhood and adolescent attention-deficit/hyperactivity disorder (ADHD) with exercise: A systematic review. Complement. Ther. Med. 2017, 34, 123-128. [CrossRef] [PubMed] 